\title{
EL EXTRAÑO ENCANTO DE LA INTERTEXTUALIDAD
}

\section{Eduardo Peñuela Cañizal}

\author{
Universidad de São Paulo
}

En un lluvioso día de septiembre de este año de 2000, empujado por las inconveniencias de la lluvia londinense o por el azar, fui a parar, casi sin darme cuenta, a la County Hall Gallery, al sitio exacto en que se organizó la exposición Dalí Universe. Ya había leído algo sobre la exposición, pero confieso que me sentí, de repente, molesto en la oscuridad de un pasillo laberíntico que ladeaba al visitante con sus paredes llenas de obras plásticas y frases del pintor catalán. Un pasillo que converge, después de una discreta curva, en una sala en donde esculturas, joyas y muebles creados por el artista forman, con su inquietante inmovilidad, configuraciones destinadas a parodiar la metáfora del centro. Cuando llegué a ese recinto, la oscuridad del ambiente se adhería a los rayos densos de las luces artificiales y en toda esa maraña de formas plásticas, arquitectónicas y cromáticas se adivinaba la presencia envolvente de un texto que se enredaba en sí mismo y esparcía ambigüedades por doquier. Un oído atento podría escuchar las voces de una enunciación con tildes de sorna o de sagacidad. La mirada de los.visi- 
tantes, sin embargo, no cesaba el interminable viaje de navegar desde una figura a otra. Era palpable el juego de las indecisiones y mucho más aún el de la incertidumbre provocada por la acumulación excesiva de obras aglomeradas de tal talante que dejaban la impresión de que el espacio de la galería se trasformaba, a cada momento, en una especie de espacio encanijado que en ellas buscaba refugio.

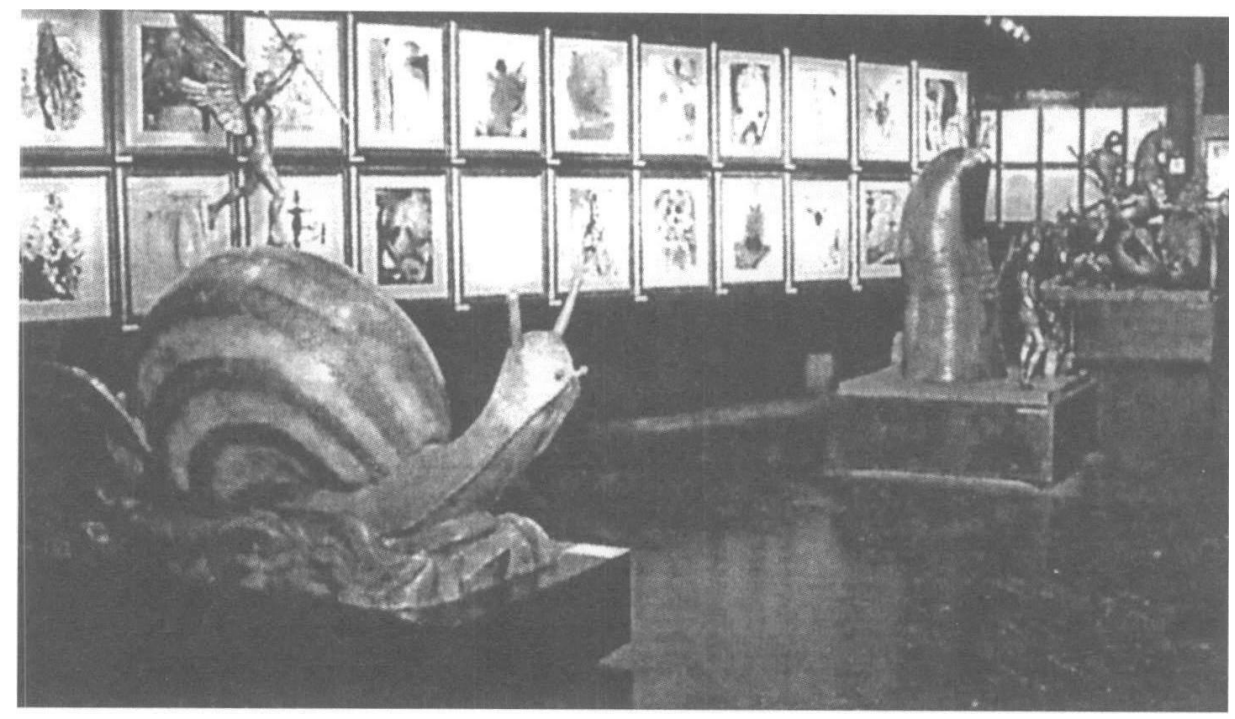

Una vez dentro de ese insólito «museo», la grandeza mecánica del London Eye y el quisquilloso bullicio de los turistas desaparecían como por encanto. La rueda gigante y los gritos caían en la trampa de una mecánica llena de ardiles que, provocadoramente, engullía, en silencio, tamaños y chillidos. Para no faltar a la verdad, de toda la circunstancia exterior restaba tan sólo la memoria de las imágenes gigantescas de unos elefantes que lanzaban al Támesis su inconfundible vocación monumental. Unos elefantes dalinianos hechos para celebrar, con sus patas invisibles de araña, algunos de los deseos que, según dicen, atormentaban a San Antonio. Para algunos, ese alarde urbano de grandiosidades rima perfectamente con el insidioso anagrama fraguado por Breton, pues, como deslumbradamente afirma Mona Crineurt, Salvador Dalí «a désormais un "musée" a sa gloire dans les beaux quartiers de Londres. Un Dalí Universe tout en démesure, sur le South Bank, voulu par Benjamin Levi collectiouneur, promoteur du maître et militant prosélyte. Le quarante-troisieme secret du livret "Cinquante Secrets Magiques" rédigé en 1947 —Faire de l'or avec sa 
peinture au propre comme au figuré- inspire l'endroit. Un universe liturgique, a la Ávida Dollars tel qu'angrammé par André Breton, ici transmué en Dalí, tout a la fois fastueux et fantaisiste, élevé dans une batisse riche d'histoire, ou se cotoient en bonne intelligence, talent art et argent» (Crineurt, 2000: 50). En el paseo que bordea el río, la fastuosidad y la fantasía exhiben su arrogancia mundana, pero, en la penumbra del interior del museo, ese alarde, con arreglo a las imágenes que mi memoria recopila, se disipa y los objetos que ahí fueron cuidadosamente puestos se prodigan en los efectos de sentido que ellos mismos producen y comparten entre sí. Porque, en el fondo, aunque cada una de esas piezas constituya un texto completo, todas juntas plasman una especie de colmena textual en la que se entretejen los panales del firmamento de significaciones fundado por Salvador Dalí.

En cada uno de los huecos de la escritura de ese texto fenomenal se depositan significados provocativos, contenidos que disimulan una isotopía desencadenadora de un constante juego de asociaciones. La unidad significante de un número se descompone en otras unidades y de un sistema de signos se pasa a otro, como ocurre, por ejemplo, en El perfil del tiempo, obra en la que el 9 del reloj se descompone en dos unidades sígnicas menores, dos significantes cuyas respectivas grafías engendran las letras iniciales de los nombres de Gala y Dalí, como se puede observar en este detalle:

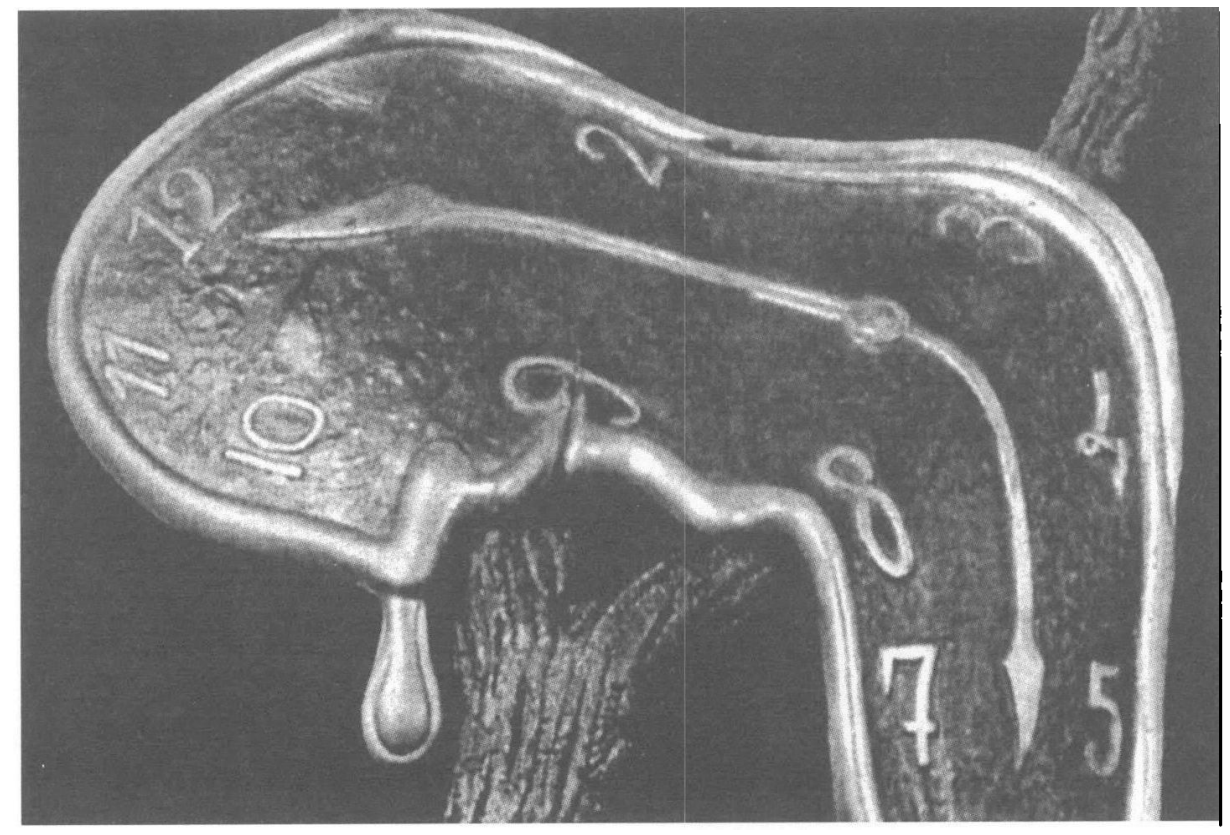


O, para citar otro caso, cuando el título de un capricho de Goya se convierte, en la recreación daliniana, en una frase que complementa el lema de la obra original, forjando un sintagma verbal en el que se congregan contenidos imprevistos. Eso es precisamente lo que sucede en la parodia que realiza Dalí del capricho ¿A dónde llevan a mamá? El texto plástico resultante mantiene una gran semejanza con el original, mas, al habérsele colocado el título de Al matadero, la ironía camuflada en la obra de Goya, irrumpe y, repentinamente, la relación entre los dos textos se contagia de sarcasmo.

El vaivén de una cosa a otra - de los signos de un sistema a los signos de otro, de conexiones que construyen un puente sintáctico entre los enunciados lingüísticos, de imágenes que reflejan las configuraciones en que se inspiran y promueven permutas semánticas sorprendentes- propaga por las obras expuestas una extraña polisemia, un semillero de sentidos en el que se gestan las más diferentes posibilidades de asociación y en el que lo ominoso prospera como por encanto. Hay momentos en los que los objetos parecen repetirse y, en esa circunstancia, mi condición de transeúnte de la galería me hizo evocar un pasaje de Freud que, ahora, transcribo: «Cierta vez que en una calurosa tarde yo deambulaba por las calles vacías, para mí desconocidas, de una pequeña ciudad italiana, fui a dar en un sector acerca de cuyo carácter no pude dudar mucho tiempo. Sólo se veían mujeres pintarrajeadas que se asomaban por las ventanas de las casitas, y me apresuré a dejar la estrecha callejuela doblando en la primera esquina. Pero tras vagar sin rumbo durante un rato, de pronto me encontré de nuevo en la misma calle donde ya empezaba a llamar la atención, y mi apurado alejamiento sólo tuvo por consecuencia que fuera a parar ahí por tercera vez tras un nuevo rodeo. Entonces se apoderó de mí un sentimiento que sólo puedo calificar de ominoso, y sentí alegría cuando, renunciando a ulteriores viajes de descubrimiento, volví a hallar la piazza que poco antes había abandonado» (Freud, 1992: 236-237).

Escribo estas líneas con la convicción de que mi viaje por la galería se asemeja mucho, en términos semánticos, a la escena del relato que acabo de transcribir. Yo también deambulé más de una vez por aquellos pasillos $\mathrm{y}$, aunque no me podía perder, también buscaba, en el fondo, una piazza en donde hallar la necesaria tranquilidad para los embates de mi zarandeada imaginación. Las callejuelas a las que se refiere Freud constituyen, considerando el sistema arquitectónico urbano, una parte marginada de la plaza vista como espacio seguro y propicio para la convivencia de personas que viven al compás de las reglas sociales, de las normas que sobredeterminan la legitimidad de los actos públicos. Las callejas, al contrario, 
se desvían de esos valores y favorecen la puesta en escena de otro tipo de actos. Facilitan, por consiguiente, la aparición del gesto prohibido, de la actitud carnavalesca o de la máscara pintarrajeada que se cuaja en el marco de una ventana. La callejuela siempre estará del otro lado de la plaza y, por analogía, del otro lado de la metáfora lexicalizada, del tropo que procura con pertinaz insistencia la calma y la protección de los lugares en donde se cobija el sosiego, la regla protectora y el embrutecimiento de la conciencia. Porque, pensando bien, lo que Freud intenta es el hallazgo del sentido denotado que se esconde en las cuatro esquinas de las connotaciones convenientemente acomodadas. Algo semejante a lo que creo que yo escudriñaba cada vez que, en la County Hall Gallery, la polisemia de las obras de Dalí se reflejaba en mis pupilas, pues no me cabe duda, de que yo también anhelaba llegar hasta sitios en que los significados resultantes de las más diversas asociaciones se entrecruzan y se condensan para erigir el obelisco de la denotación añorada.

Los ojos de uno de los lienzos que sirvió de escenario para la pesadilla de Spellbound plantean incógnitas. Unos ojos que flotan sueltos por el espacio plástico de la tela y lanzan sus destellos alardeando magnetismos y, acribillando la mirada de quien los contempla, multiplican desorbitados asombros para dejar en el recinto de la galería hilachos de perplejidad. Uno de esos hilachos enhebra las agujas del sentido y con ellas suturo la herida ancestral de la duplicación de esos ojos que se abren de par en par, la herida acerca de cuya zanja nos susurra algo la figura que se dibuja en esa esfera cósmica de la parte superior izquierda de la tela, porque, como afirma Freud, el carácter de lo ominoso sólo puede estribar en que el doble es una formación oriunda de las épocas primordiales del alma ya superadas. Es, por lo tanto, un

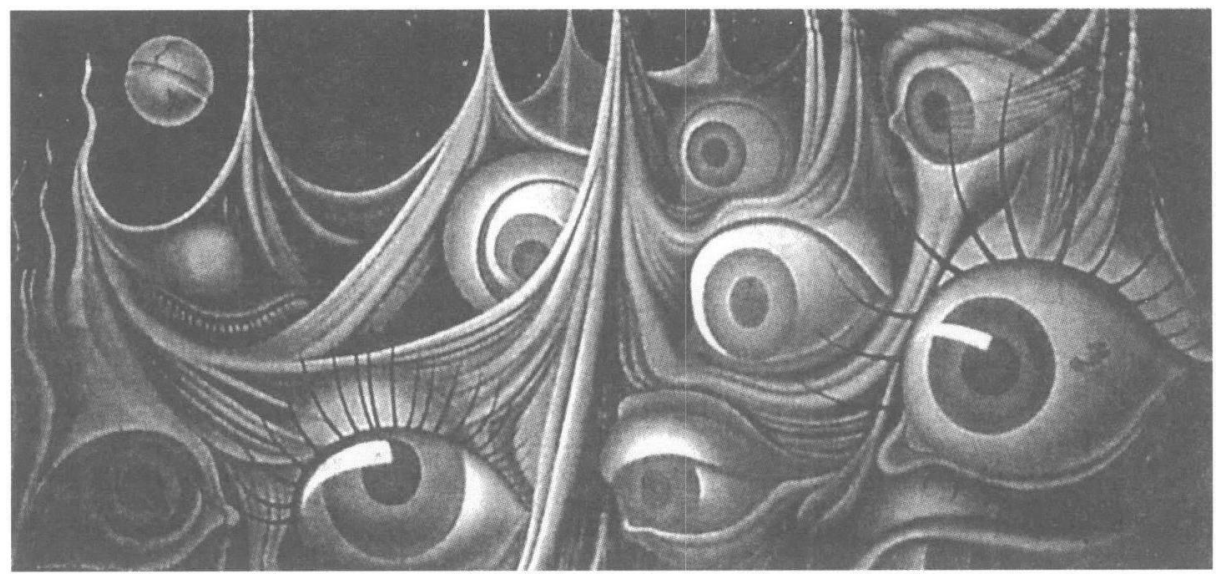


motivo que nos abre las puertas de la regresión, que nos conduce hacia cosas remotas, hacia objetos en los que el deseo tiene sus raíces más hondas, hacia la nostalgia de momentos en que el yo aún no se había deslindado del mundo exterior.

Quizás sea la ominosidad una especie de sustancia semántica, en la acepción de la glosemática, que asume formas a través de las configuraciones resultantes de las relaciones de unas imágenes con otras o, mejor dicho, de las relaciones sobredeterminadas por imágenes diferentes que guardan entre sí algún tipo de analogía. Si, como prueba Freud, la repetición es uno de los indicios más característicos de lo ominoso, la imagen que refleja, de alguna manera otra imagen, propende a establecer vinculos en que algunos aspectos se reiteran. La disposición, pues, de ese lienzo en el que los ojos se multiplican sugiere direcciones y arrastra la mirada del observador tanto hacia lugares existentes en el interior de la galeria como hacia esferas cuya existencia es fruto de nuestra imaginación. El cuadro fue puesto contra la pared que queda junto a una escalera que desciende a un sótano, cuya entrada, al menos el día de mi visita, estaba vedada. Al no tener ningún tipo de marco, la tela le hacía ventanas a la oscuridad y la escalera pasaba a funcionar como algo adicional que, sin dejar de ser parte del espacio arquitectónico, le ponía fronteras al enunciado de la pintura y, consecuentemente, lo enmarcaba. Con eso quiero decir que la escalera no era simplemente algo que estaba fuera de campo ni tampoco fuera de marco. Adjudicándose el papel del marco, la escalera instauraba la paradoja de repetir un elemento que le faltaba a la pintura. $O$, en otras palabras, la escalera oscilaba, en el momento en que yo contemplaba el cuadro, entre ser sencillamente una escalera y repetir el borde inferior del cuadro.

Me inclino a aceptar, ahora, que la relación que de ese modo se instauraba entre el cuadro y la escalera se presentaba a mi intuición como una forma posible de la ominosidad. No sólo porque la escalera repetía el borde del cuadro, sino también porque lo duplicaba y, tal vez por eso, la forma expresiva que se manifestaba en el instante de mirar el cuadro inscribía en el enunciado pictórico una dualidad de semiosis: por un lado, los significantes plásticos del cuadro, aliados a los significantes eidéticos y texturales (Groupe $\mu, 1992$ : 318-342), conducen a una determinada lectura de la obra - la lectura, por ejemplo, que prevalece en la película en la cual el cuadro fue parte del escenario de una secuencia onírica- y, por otro, los significantes del enmarcado posibilitan, en este caso, alternativas de interpretación diferentes a la mencionada. Una de ella, para ilustrar la cuestión, puede ser la que surge cuando uno 
se percata de que el cuadro «está concebido en general para verse verticalmente: ocupa, pues, su lugar entre los objetos verticales y, conforme con una de las más seguras constantes de nuestra experiencia -incluso visual, como han observado los teorizadores "ecológicos" de la percepción-, pesa, está sometido a la gravedad, no sólo porque los objetos representados se fantasman como pesados, sino porque las "masas visuales" mismas (Arheim) tienden a anclarse en el suelo, a "caer". Dicho de otro modo, el borde inferior del cuadro es aquél sobre el que, literalmente, se apoya todo. Es extraño que desde ese momento que ese borde dimane casi siempre de un tratamiento particular, que tiene en cuenta esa función de suelo y basamento perceptivos e imaginarios» (Aumont, 1997: 90). Siendo así, la potencialidad de asociación que ese fragmento del escenario de Spellbound ostenta se canaliza, en la imaginación del espectador, hacia el misterio de lo de abajo, hacia el hechizo del sótano, metáfora ya clásica para designar el inconsciente. Invita, seguramente, a una interpretación que remolca las fuerzas imaginarias del observador al simbolismo lóbrego de lo subterráneo y, en ese caso, hemos de convenir que la relación entre el borde inferior del cuadro y la escalera que baja al sótano no es fortuita.

Todo lo expuesto constituye, en principio, una tentativa de demostrar que el «museo», con todos los objetos que en él se exponen, es un texto fenomenal, un texto efectivo en el que lo afectivo se sobrepone a lo inteligible o, por lo menos, acapara la sensibilidad de quien por él transita y vive algunos de sus aspectos tensivos, porque, al lidiar con la temporalización que se manifiesta a través de la disposición de las obras componentes del texto del «museo», no puedo dejar de incluirme entre los que defienden una semiótica que rechaza, con más o menos vehemencia, el privilegio atribuido a lo inteligible, ya que, como afirma Claude Zilberberg, el lugar asignado a lo sensible no debe ser concesivo, pues la «armazón» del sentido «es ciertamente modal, o más exactamente, tiene por fundamento un complejo modal que asocia la eficiencia y la fiducia, la eficiencia de un poder atestiguado por un sentir, medido, a su vez, por un creer» (Zilberberg, 2000: 203). Desde ese punto de vista, lo que en verdad me interesa, para delimitar la extensión del propósito de este trabajo, es sondear, aunque sin pretensiones de ir muy lejos, el papel de lo ominoso en los procesos de intertextualidad.

Uno de los datos que preservo de las sensaciones vividas al ponerme en contacto con el texto fenomenal del «museo» proviene de la disposición de las obras, ya que, con ese recurso, se armó una capa cuya extensión espacial no sólo acoge la ansiedad perceptiva de los espectadores, 
sino que también estimula en ellos diversas posibilidades de asociación, de traer al acto de esa confrontación vestigios de las experiencias vitales del pasado que cada uno de los sujetos observadores lleva dentro de sí. Recuerdo, por ejemplo, que los grabados de Dalí inspirados en los caprichos de Goya fueron dispuestos de la siguiente manera: en la parte superior de cada uno de ellos estaba el capricho goyesco correspondiente. Tal programación obligaba a que la mirada de los observadores recorriese forzosamente una imaginaria línea vertical y, después de vivenciar la comparación, se detenía en la parte inferior de esa línea y allí la imaginación, adentrándose en los reinos de los mundos inferiores, encontraba terreno propicio al devaneo carnavalesco, en el sentido que Bajtín atribuye a esta palabra. Se veía compelida, por decirlo así, a entregarse a los más variados devaneos, pues, en el fondo, la fantasía de los espectadores ya estaba impregnada de los rasgos surrealistas que imperaban en todo el ambiente, tanto en los objetos tridimensionales como en las ilustraciones que remitían a las ejemplares locuras de Don Quijote o a los delirios eróticos del Marqués de Sade.

En lo que se refiere a mí, preservo la sensación de que ese enjambre de configuraciones me evocaba mucho el atavismo del que, con tanta frecuencia, nos habla Dalí en sus escritos, principalmente en El mito trágico del «Ángelus» de Millet. El cromatismo amarillento que emanaba de buena parte de las imágenes se mezclaba con la penumbra del ambiente y, como remedo casi metafórico de lo crepuscular, insistía en notificarme el apego de las sediciones ancestrales. Pero no era sólo eso. El título del grabado reproducido abajo me persuadió de que mis impresiones no eran gratuitas, ni tampoco frutos vagos de un fenómeno delirante secundario. La imagen obsesiva estaba, nítida, en mi frente y ella me dibujaba ese rumbo fantasmagórico.

En el fondo, no era de lo disparatado de la metáfora goyesca que provenía esa propensión mía a lo atávico. Creo ahora, reviendo la parodia daliniana, que el origen de tal sentimiento está en la soledad del paisaje campestre y, sobre todo, en la iconografia de El gran masturbador que se esboza en el segmento superior del grabado.

Para el pintor catalán, la productividad delirante, no es, en el caso del Ángelus, «de orden visual sino sencillamente psíquica. No es la imagen que cambia desde el punto de vista morfológico, sino que, desde el punto de vista del argumento, desde el punto de vista del drama, es posible (como en el caso del rostro paranoico) objetivar y hacer comunicable una transformación completa» (Dalí, 1978: 41). Me parece que esas ideas de Dalí se aproximan, en cierta medida, a los 


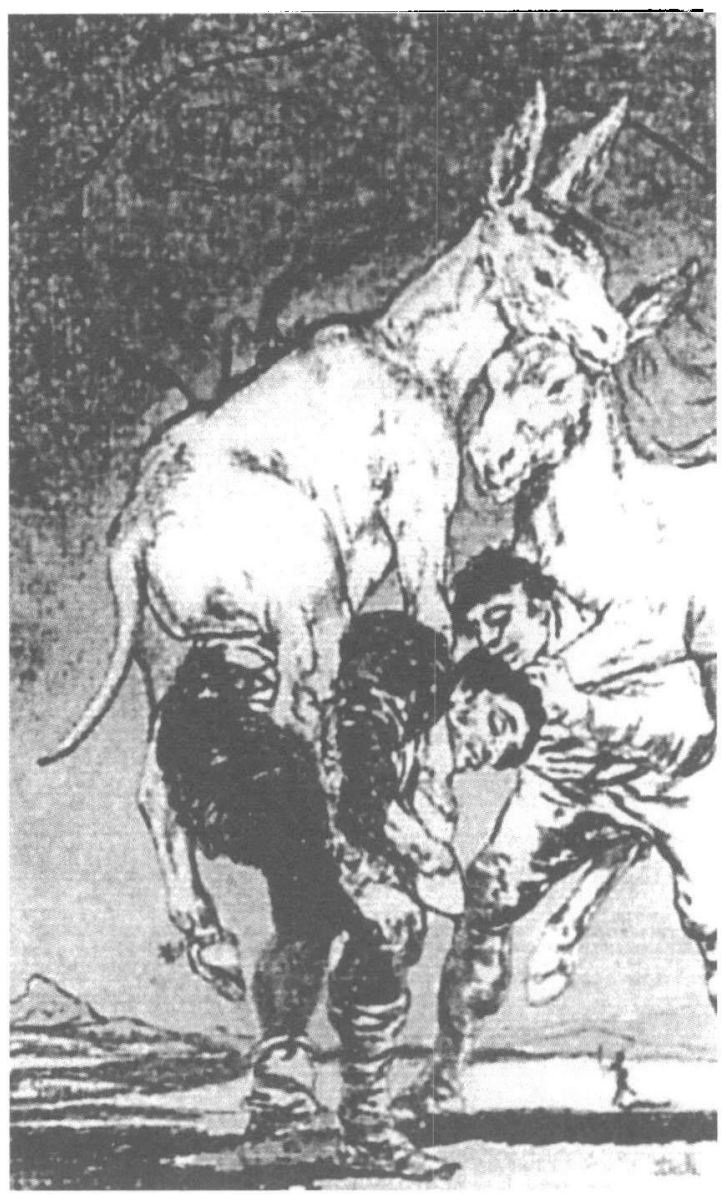

Piensa en el Ángelus de Millet.

conceptos que fundamentan los dos tipos de intertextos que la semiótica distingue en la actualidad: de un parte, el intertexto material y, de otra, el estructural. El primero es observable en la analogía existente entre el capricho de Goya y la recreación del mismo hecha por Dalí. Los elementos morfológicos creados por el aragonés se mantienen, casi en su totalidad, en la obra del catalán, lo que deja en evidencia una relación analógica, basada en la materialidad de los signos visuales, entre los dos textos. El segundo es el resultado de la imitación de la estructura o, si se quiere, de la reproducción en otro texto de la ideología del texto original. Eso ocurre también en la parodia de Dalí, pues, en el espacio plástico del grabado, conforme a lo que insinúa su título, se infiltra el significado del mundo de los campesinos explotados, 
tema que sirve de base al capricho de Goya, ya que, según la interpretación de Alcalá Flecha, la lamentable «situación de los campesinos, que habían de mantener con sus trabajos la carga intolerable de la ociosa nobleza y de los frailes holgazanes, es abordada resueltamente en los Caprichos, con el mismo espíritu crítico con que se censuraba en numerosos escritos coetáneos» (Alcalá Flecha, 1988: 140).

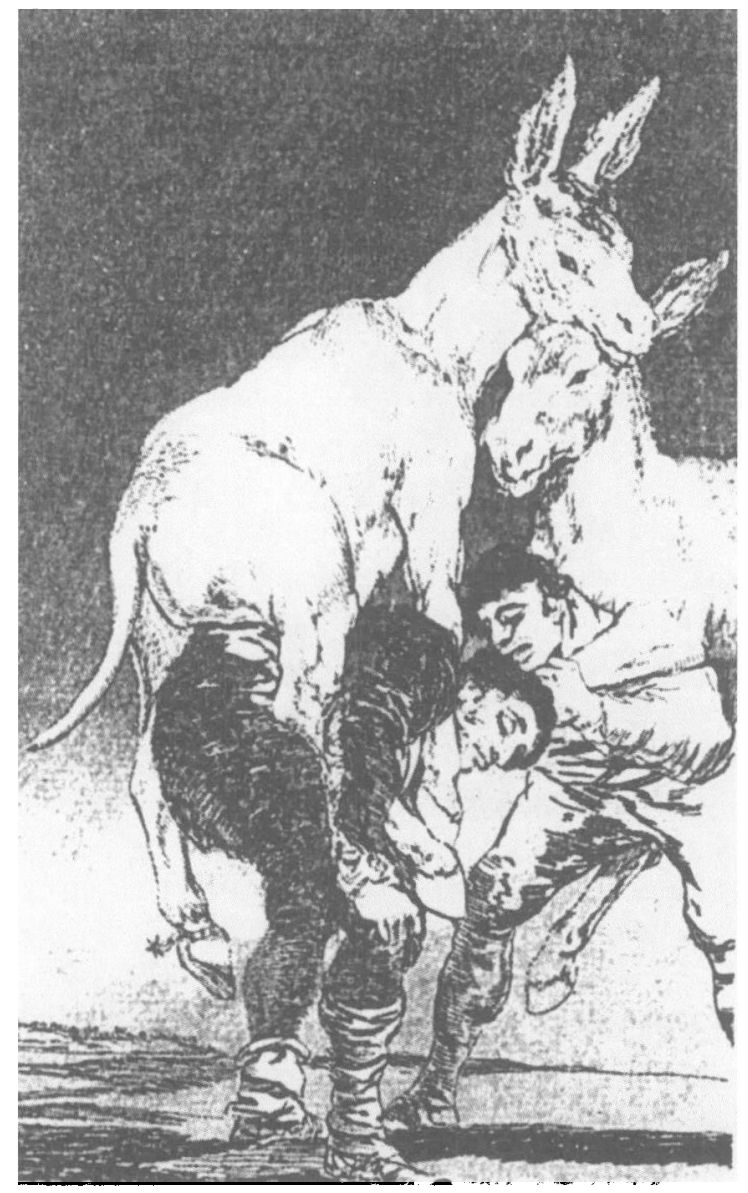

Sin embargo, si comparamos el texto plástico de Dalí con el del capricho Tú que no puedes podremos constatar que la obra de Dalí supera los compromisos político-sociales patentes en el aguafuerte goyesco. Eso no quiere decir que el grabado del pintor catalán no reproduzca, también, el intertexto estructural que se manifiesta en el capricho parodiado. Se sabe, por ejemplo, que el capricho de Goya 
mantiene una estrecha relación intertextual con obras literarias de su tiempo y, de modo muy especial, con el castizo refrán: «Tú que no puedes, llévame a cuestas». Esa intertextualidad, sea cual fuere su modalidad, es precisamente una de las claves de la estructura sobre la que se ordena la composición de la obra y, a su manera, Dalí la imita por el hecho de que el título de su grabado se refiere al famoso cuadro de Millet y, a su vez, la silueta esbozada en la parte superior se refiere al no menos famoso cuadro $E l$ gran masturbador. No cabe duda, por lo tanto, de que el principio estructural de la intertextualidad del aguafuerte que inspira al pintor de Figueres se preserva en la parodia que él hace de la obra de Goya. Puede argumentarse, eso sí, que la intertextualidad de Tú que no puedes coloca en relación textos verbales y textos plásticos, mientras Piensa el Ángelus de Millet lidia con una relación en la que los textos iconográficos son preponderantes. Pero eso, dígase de paso, es tan sólo una diferencia de escritura, ya que Dalí, como buen surrealista, se mantiene fiel a un tipo de discurso en el que las imágenes dicen más que las palabras.

Hay que señalar, desde el punto de vista de una isotopía latente, que la comparación entre esas dos obras pone de relieve la cuestión del erotismo, sobre todo cuando se descubre, a través del esbozo, la presencia de la figura del masturbador daliniano, composición iconográfica presente, en cuanto estilema plástico, en muchos de los cuadros del pintor catalán. En el caso del aguafuerte de Goya, el sesgo erótico no aparece de manera explícita, pero se insinúa de modo sutil a través de un conjunto de detalles que, vistos con atención, causan, en un primer momento, una impresión extraña. Es el caso, por ejemplo, de la pata del asno que aparece entre las piernas del campesino de la derecha. Su forma y el lugar en que fue colocada no son componentes necesarios en una representación de carácter icónico. La pata del cuadrúpedo podría muy bien no estar en el campo de lo visible, pues, sin ella, la composición no sufriría ninguna alteración substancial si se considera la finalidad de la metáfora estructurada por Goya para expresar grotescamente la explotación de los hombres rurales, ya que, con arreglo a la lectura de Alcalá Flecha, la iconografía «de la insólita composición, con la multiplicidad de significados que es frecuente en la obra del aragonés, enriquece aún más la intención de su crítica: la representación de los asnos como jinetes convierte a éstos en caballeros, dando lugar a la asociación borricos-caballeros-nobleza. Quedan identificados, pues, según el ingenioso juego de asociaciones que propone el grabado, los asnos son los caballeros, es decir, con la nobleza, se trataría en este caso no de una censura de la clase parásita en general, sino de una alusión concreta a la aristocracia 
ociosa e inútil que vivía a costa de la miseria campesina» (Alcalá, 1988: 140-141). De todo eso se deduce que la posición de la pata del borrico poco o nada representa, si tenemos en cuenta los tres niveles de sentido establecidos por Roland Barthes (1986: 49-65) para el nivel informativo o para el simbolismo de la metáfora visual. No ocurre lo mismo con la pata izquierda del borrico que está en primer plano: la espuela, aunque atente contra lo informativo, refuerza, sin embargo, el sentido simbólico y emblemático de la metáfora. Por lo dicho, el significado de la pata del cuadrúpedo entre las piernas del campesino debe ser entendido en el nivel de lo que Barthes entiende por sentido obtuso.

Para el conocido semiólogo francés, el sentido obtuso tiene algo que ver con el disfraz y se presenta bajo la figura de un hojaldre de contenidos que siempre permite sustituir al sentido precedente, como en una formación geológica. Su función es «decir lo contrario sin renunciar a lo contradicho». O sea, su función, en el fondo, es retórico-poética en razón de las rupturas, de los «escándalos» que produce su presencia en el espacio semiótico de un texto. En ese caso, la pata ofusca la información icónica y se ofrece a la percepción del observador como si fuese una máscara en la que se disfrazan gestos y actitudes. Pero, al mismo tiempo, esa especie de tapujo que se manifiesta en la extraña posición de la pata alude a un sentido obtuso que depende, en principio, de la manipulación pictórica que el artista, consciente o inconscientemente, hace de las acciones y gestos representados. Según Burgin, el concepto de «tableau has a history prior to Diderot: humanist scholars of the mid-sixteenth century elaborated a theory of painting which they based on isolated remarks in the writings of classical author. From Aristotie's Poetics they took the doctrine that the highest calling of any art is to depict human action in its most exemplary forms; the human body, they held, was the privileged vebicle for the depiction of such "histories". The consequent programme of so-called "history painting", which dominated painting in the West from the mid-sixteenth to the mid-eighteenth centuries, was elaborated in great detail in the body of humanist art theory now known by the emblematic slogan "ut pictura poesis" "as is painting, so is poetry"- a device abstracted from the Ars Poetica of Horace, which the Renaissance reversed in emphasis to establish the dependency of the visual image on the written text. As the painter of "histories" had to show in a single instant that which took to unfold, then that instant had to have a singularly privileged position within the total action. It was therefore recommended that the moment selected by the painter for visualization shouid be the peripateia, that instant in the course of an action when all hangs in the balance» (Burgin, 1986: 86). 
Teniendo en cuenta las particularidades de esa especie de código al que se refiere Burgin, la pata del cuadrúpedo fue paralizada, en el texto pictórico, exactamente en ese instante de una acción en la que todos los componentes parecen protagonizar el curso de una acción when all hangs in the balance. Con tal recurso, los signos visuales adquieren propiedades tensivas que los liberan de la rigidez de las normas y, frecuentemente, toman formas adecuadas a los requisitos más característicos de las configuraciones propicias al aparecimiento del sentido obtuso. Así acaece en el caso del grabado goyesco: la acción representada no es sencillamente una acción que tiene por referencia esa disparatada cabalgada. Instituye, también, una monta, con todas las connotaciones sexuales que el vocablo tiene en castellano. Entre esas dos isotopías semánticas, los gestos y las actitudes plasmados en el grabado de Goya generan un significado que sustituye los sentidos precedentes y, sin anular lo contradicho, impone un contenido que se aproxima a lo ominoso.

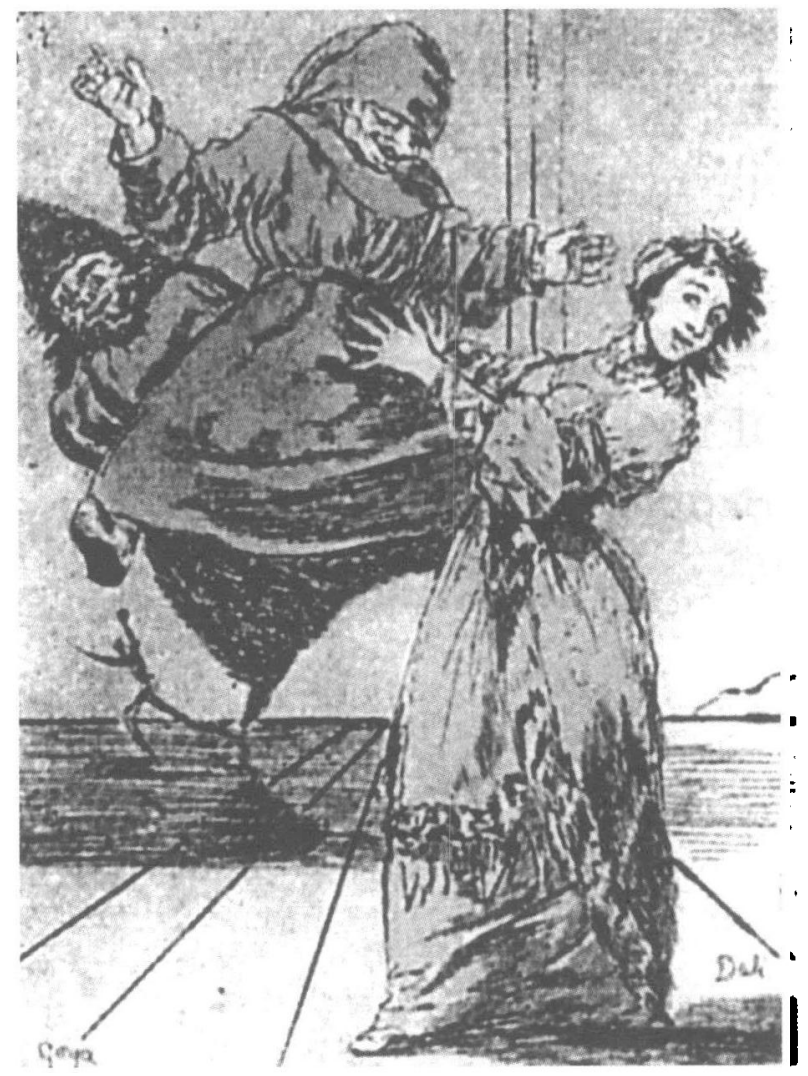

No grites, tonto. 
Los intertextos materiales moldeados por Dalí son fruto, a menudo, de un trabajo destinado a descifrar los sentidos latentes que se ocultan en el hojaldre semántico de los gestos goyescos. En el grabado arriba trascrito, cuyo título en la obra original es No grites, tonta, Dalí monta su interpretación a partir de la ambigüedad de que se reviste la peripateía del gesto efectuado del personaje femenino. No se sabe, en verdad, si las manos de la mujer significan aceptación o repulsa. La acción representada quedó paralizada en un instante que favorece la irrupción de un bisemismo aparentemente contradictorio: de una parte, en cuanto encarnación ardilosa de la figura del duende, el deseo del fraile $y$, de otra, el tal vez fingido rechazo de la joven. De cualquier manera, el contexto histórico-social que se refleja en el aguafuerte permite las dos lecturas. Estos versos citados por Alcalá Flecha (1988: 57-58) lo atestiguan:

\author{
También yo estaba contenta, \\ Porque el duende era mi amigo, \\ Y nunca a mí me asombraba, \\ Sino me hacía cariños. \\ Mire usted, los tales duendes \\ A los hombres intimidan; \\ Mas para nosotras, todos \\ Son de mercocha y almíbar.
}

Sólo que Dalí, al hacer de la mujer el sujeto que dice la frase del título, neutraliza el papel activo del fraile-duende y reitera con eso el erotismo que se «moralizaba» en el grabado original. El paisaje ideado por el pintor catalán, escenario ya emblemático de muchos de sus cuadros dedicados a la temática erótica, confirma, creo, esa interpretación.

Los casos de intertextualidad aquí comentados, aunque de manera muy simplificada, evidencian, entre otras cosas, que los intertextos creados por Dalí propenden a valorar los procesos de regresión. Los intertextos materiales, debido a la minuciosa semejanza que mantienen con los textos parodiados, se presentan, teniendo en cuenta el contexto cultural al que pertenecen, con matices de familiaridad. Se tiene la impresión, cuando los contemplamos, de que esa familiaridad resulta casi obvia, pero, como creo haber dejado claro, los grabados dalinianos traen al espacio semiótico en que se configuran un tipo de expresividad que conforma significados cuyo origen está, por decirlo así, del otro lado de la obviedad y esa particularidad rescata de modo muy sutil rasgos de lo ominoso. Es constante, por ejemplo, la tendencia 
daliniana a transformar el escenario en el que Goya coloca a los personajes de sus caprichos. El paisaje rural de No grites, tonta aparece, en el intertexto de Dalí, asumiendo una configuración construida de acuerdo con las normas de la perspectiva geométrica renacentista y, por eso, la figura humana que se pierde al fondo de ese panorama, adquiere un talante infantilizado, fenómeno expresivo que le confiere al grabado un sesgo de familiaridad, un acento que ya es una tónica en la pintura de Dalí, principalmente en la representación de esos panoramas solitarios, que recuerdan la geografía de los alrededores de Figueres, en los que la silueta de un niño gesticula como si con ello quisiese espantar su asombro o juega con un aro para tranquilizar sus inquietudes infantiles. La repetición de ese sintagma pictórico termina provocando una sensación de extrañeza y, a partir de ahí, el salto a lo ominoso es inevitable, como se puede constatar también en el intertexto inspirado en el capricho Tú que no puedes.

Pienso, por consiguiente, que la intertextualidad actualiza, siempre, un proceso de repetición y, en ese caso, despliega un mecanismo compulsivo que simboliza la ansiedad de retorno, de volver a la infancia y, aún, de sueño nostálgico de lo intrauterino, asunto del que Dalí habla en sus escritos. Sin entrar en detalles de cuestión tan compleja, deseo únicamente formular la hipótesis de que si, de un lado, el intertexto material duplica, de otro, el intertexto estructural se hace convulsivo en los juegos de intertextualidad fraguados por Dalí. Tal fenómeno no ocurre exclusivamente en los grabados que tienen como fuente de inspiración los caprichos goyescos. Se realiza también cuando Dalí se inspira en las obras del Marqués de Sade, de Cervantes, de Casanova, de Bocaccio, de Ovidio y de otros más. Creo, en fin, que el extraño encanto de la intertextualidad proviene de lo ominoso o, mejor dicho, de la ominosidad que los intertextos estructurales forjados por Dalí proyecta en los intertextos materiales destinados, casi siempre, a repetir imágenes ya existentes y, por eso mismo, a perpetuar un inquietante deseo de regresión.

\section{Referencias bibliográficas}

AlCAlÁ Flecha, Roberto (1988). Literatura e ideologia en el arte de Goya. Zaragoza: Diputación General de Aragón.

AumonT, Jacques (1997). El ojo interminable. Barcelona: Paidós. 